\title{
Erratum to: The Mitochondrial Permeability Transition Pore and ATP Synthase
}

Gisela Beutner, Kambiz N. Alavian, Elizabeth A. Jonas, and George A. Porter, Jr

(C) Springer International Publishing Switzerland 2016

Handbook of Experimental Pharmacology, DOI 10.1007/164_2016_5

The publisher regrets to inform that the one of the author name was incorrect.

The correct name is Kambiz N. Alavian (wrong: Alavian N. Kambiz).

The updated original online version for this chapter can be found at DOI 10.1007/164_2016_5

G. Beutner • G.A. Porter, Jr $(\bowtie)$

Division of Cardiology, Department of Pediatrics, University of Rochester Medical Center, 601

Elmwood Ave., Box 631, Rochester 14642, NY, USA

e-mail: george_porter@urmc.rochester.edu

K.N. Alavian

Division of Brain Sciences, Department of Medicine, Imperial College London, London, UK

E.A. Jonas

Department of Internal Medicine, Section of Endocrinology, Yale University, New Haven, CT, USA

(C) Springer International Publishing Switzerland 2016

Handbook of Experimental Pharmacology, DOI 10.1007/164_2016_87 